\title{
Parental Attachment, Peer Attachment, and Delinquency among Adolescents in Selangor, Malaysia
}

\author{
Lim Jia Choon ${ }^{1}$, Muslihah Hasbullah ${ }^{1}$, Sa'odah Ahmad ${ }^{1} \&$ Wu Shin Ling ${ }^{1}$ \\ ${ }^{1}$ Department of Human Development and Family Studies, Universiti Putra Malaysia, Selangor, Malaysia \\ Correspondence: Muslihah Hasbullah, Department of Human Development and Family Studies, Universiti Putra \\ Malaysia, 43400 UPM Serdang, Selangor, Malaysia. E-mail: muslihah@upm.edu.my
}

Received: July 22, 2013 Accepted: September 3, 2013 Online Published: October 29, 2013

doi:10.5539/ass.v9n15p214 URL: http://dx.doi.org/ass.v9n15p214

\begin{abstract}
This study aimed to investigate the relationships between parental attachment, peer attachment and delinquency among adolescents. 480 adolescents aged 13-17 were randomly selected from four secondary schools in Malaysia. The revised version of the Inventory of Parent and Peer Attachment (IPPA) (Armsden \& Greenberg, 1987) and the Self-report Delinquency Scale (Mak, 1993) were used in this study. The results revealed significant negative relationship between father and mother attachment with adolescents' delinquency and significant positive relationship between peer attachments with adolescents' delinquency. Statistically significant differences were obtained for males and females adolescents where males are more delinquent than females. Multiple regression analysis showed that gender is the strongest predictors for adolescents' delinquency, followed by peer attachment, mother attachment and father attachment. Practical recommendation and implementation are discussed where attachment could be included as a target for implementing intervention.
\end{abstract}

Keywords: parental attachment, peer attachment, adolescents, delinquency

\section{Introduction}

Delinquency among adolescents has become a serious phenomenon in our country. Juvenile delinquent behavior refers to the behavior committed by someone below eighteen years old where it violates the criminal law (Houston \& Barton, 2005). These delinquent behaviors can range from less severe behaviors such as abuse the school rules, absentee, school truancy, cigarette smoking, and vandalism to more severe crime such as stealing, robbery, substance abuse, rape, and weapon possession.

Different countries have different cultures and laws, thus juvenile delinquency is also defined differently among countries and cultures. Malaysia consists of people from different ethnics and cultural backgrounds. There are three main races in Malaysia which are Malay, Chinese, and India. The religiosity among these races is different although some may have similar culture identity. For instance, Malays who are Muslims are not limited only to the civil law. They are also judged based on the Syariah law for behaviors that are against their religion. Example of behaviors that are against the Syariah law includes consumption of alcoholic drinks, not fasting during the fasting month, close proximity, and improper dressing and behaviors which are considered inappropriate in their religion. Chinese, Indian, and other races are not entitled to the Syariah law unless they have converted to Islam (Adibah, Melati \& Zuria, 2013; The Commissioner of Law Revision, Malaysia, 2006).

Based on the law in Malaysia, juvenile delinquent refers to a young person who had committed a criminal offence and was given a court order (Maznah, 2007). The Malaysian Ministry of Education stated that delinquency in school include both violation of the Penal Code as well as the school norms. Student may be punished by the school authorities for misconduct behaviors such as vandalism, fighting, smoking, truancy, and some minor misbehavior which include disrespect to others, impoliteness, inappropriate or messy school attire or appearance, and bringing items that are banned to school such as hand phone.

However, students who committed serious offences which include the violation of the criminal law are handed over to the police force for investigation. The Prison Department of Malaysia detains juveniles aged between 14 to 21 years in prison as young prisoners. Juveniles are also being detained in Henry Gurney School as students where they are being educated (Maznah, 2007).

In Malaysia, juvenile cases have risen steadily since 2002. Daily newspaper reports with new titles such as “Mat 
Rempit", "Bohsia and Bohjan", "Infanticide", "Drug Abuses", "Rape", and "Abortion" that frequently appeared at the front page of our local newspapers are the evidences of the increasing delinquency behaviors among adolescents. Based on the news report, the police recorded 6048 juvenile cases in 2009 compared with 2955 cases in 2002. More seriously, violent crimes such as rape, molest, and armed robbery were almost doubled as there were 1,105 cases in 2002 compared with 2394 cases in 2009 (Hariati, 2010, November 7). Based on the Drug Report (2012) by the National Anti-Drug Agency of Malaysia, from January 2012 to September 2012, among 6935 drug abusers, young people were comprised of 4618 abusers.

In 2011, there are 5547 juvenile cases in Malaysia where males involved in 5270 cases while females involved in 277 cases. In terms of ethnicity, juvenile delinquency is the highest among Malays (4357 cases), followed by Indian (389 cases), Chinese (352 cases), natives of the State of Sabah (230 cases), natives of the State of Sarawak (122 cases), others ( 88 cases), and natives of the Peninsular Malaysia ( 9 cases) in 2011 (Department of Social Welfare, 2013).

Statistics have shown that the delinquency in Malaysia especially juvenile delinquency is becoming more serious and this problem will continue to increase if appropriate action is not taken. Due to the increase rate in juvenile delinquency, researchers have been investigating many areas that cause the delinquent problems among adolescents. One of the main factors that become a concern for the rising of juvenile delinquency is the attachment with family and friend (Hoeve et al., 2012; Immele, 2000).

Attachment is the emotional bonding with someone that endures across time and space. Children started to be attached to their primary caregivers since birth (Ainsworth, 1969). Secure attachment where the caregivers are able to respond to the children's needs appropriately allow the children to feel secure and comfort. This secure attachment with the caregivers also serves as a secure base for the child to explore the world around them (Bowlby, 1971). However, during adolescence, the attachment figures may shift to other figures which are non-caretakers such as peers (Hoeve et al., 2012). Peer attachment is also an important aspect as the positive support and care from the peers encourage adolescents to face challenges better. However, if the adolescents are attached to delinquent peers, they are more likely to be involved in delinquent behaviors (Daigle, Cullen \& Wright, 2007). Despite the shift in attachment figures, the parent-child attachment still impacts the child as it persists throughout the lifetime (Armsden \& Greenberg, 1987).

Children who experience secure attachment with the caregivers and peers result in positive outcomes such as higher self-esteem, better academic achievement, better emotional regulation and higher social competence (Bergin \& Bergin, 2009; Hoeve et al., 2012). In contrast, children who experience poor attachment with their caregivers and friends are more likely to result in negative outcome such as behavioral problems and delinquency (Elgar, Knight, Worrall \& Sherman, 2003; Hoeve et al., 2012).

In addition, past researchers found that there is a difference in delinquent behaviors between males and females. It was found that male involved more in delinquent behaviors compared to female (Daigle, Cullen \& Wright, 2007; Hart \& Mueller, 2013; Hoeve et al., 2012). In terms of the severity, female tend to commit less severe behaviors such as lying, stealing, and bullying compared to male who involved in robbery and violent behaviors (Hart \& Mueller, 2013; Weerman \& Hoeve, 2012). Baker (2006) stated that in early childhood, males are more likely to have behavioral problems compared to females. However, in adolescents' stage, the involvement of females has increased rapidly narrowing the gender differences gap in delinquent behaviors in the recent years.

Due to the rise and severity of the juvenile delinquent in Malaysia, this study aims to investigate the relationships between parental attachment, peer attachment and delinquency among adolescents in the State of Selangor, Malaysia. This study also aims to compare the differences in delinquency among male and female adolescents. In addition, this study aims to determine the unique predictors of delinquency among adolescents in Selangor.

\section{Methodology}

\subsection{Sample and Procedures}

In this study, the State of Selangor was chosen among all the other thirteen states in Malaysia to conduct this study. This is due to the juvenile cases in Selangor are averagely the highest among all state in Malaysia since 2002. More seriously, the juvenile cases have increased up to $38 \%$ from 2005 to 2007. In 2011, there are a total of 532 juvenile cases in Selangor which is the second highest among all states in Malaysia. Among these juvenile cases, male adolescents contributed 517 cases while female adolescents contributed 15 cases only (Department of Social Welfare, 2013).

In Selangor, there are 9 districts. From these 9 districts, 2 districts where randomly chosen. Then, 4 secondary schools where also randomly selected from each of the chosen districts. Thus, the respondents consisted of 480 
adolescents aged from 13 to 17 whom were also selected randomly from four secondary schools in Selangor, Malaysia. The selected schools were from the urban area. Urban area was chosen as the delinquent rate in the urban area is higher than the rural area. Adolescents living in urban area have higher risk in involving in delinquent activities due to the characteristics of the urban area where higher crime rates and poverty occur (Department of Social Welfare, 2013; Gorman-Smith, 2008).

The respondents were selected using non-proportionate stratified random sampling where 240 male and 240 female adolescents were selected. Approval from the Malaysia Ministry of Education, Department of Education in Selangor, schools' principals and counselors were obtained through standard procedure. Then, self-administered questionnaires were distributed to the adolescents where consent from the participated students was obtained. Instructions in answering the questionnaire and confidentiality of the study were explained to the students. Questionnaires were promptly collected upon completion of questionnaire.

\subsection{Measures}

The revised version of the Inventory of Parent and Peer Attachment (IPPA) by Armsden and Greenberg (1987) was used to measure the adolescents' attachment with three important figures such as father, mother and peer. The IPPA consists of 3 parts where each part consists of 25 questions to access the adolescents' attachment with their father, mother and peer. It is a five-point Likert scale ranging from almost never or never true to almost always or always true. Higher score indicates higher attachment with that particular person figure. Some examples of the items for mother figure include "My mother respects my feelings." and "I feel my mother does a good job as a mother." For father figure, some examples of the items are "My father accepts me as I am." and "I like to get my father's point of view on things I'm concerned about." The items for peer include "My friends can tell when I'm upset about something" and "When we discuss things, my friends care about my point of view." In the present study, the Cronbach's alpha for father attachment, mother attachment and peer attachment were $.838, .841$, and .862 respectively.

The Self-Report Delinquency Scale (Mak, 1993) consists of 40 items to measure the delinquency among adolescents. This scale measures whether the respondents have engaged in various delinquency activities in the past 12 months by answering yes or no to the questions. The score ranges from 0 to 40 where higher score indicate higher engagement in delinquency activities. The items include "Driven an unregistered car?", "Stolen things or parts out of a car or a motor bike?", and "Done something that your parents did not want you to do?" The Cronbach's alpha in this present study was .922.

\section{Results}

The data obtained was analyzed using SPSS to describe all the variables and to investigate the relationships between parental attachment, peers attachment and delinquency among adolescents. In this study, there were 480 respondents consisted of 240 male and 240 female aged 13-17. Firstly, Pearson Product-Moment Correlation is used to test the correlations between father attachment, mother attachment, peer attachment and delinquency among adolescents. Then, t-test is used to compare the differences in father attachment, mother attachment, peer attachment, and delinquency between male and female adolescents. Lastly, multiple regressions are used to find the predictors of delinquency among adolescents.

Table 1. Correlations between father attachment, mother attachment, peer attachment and delinquency among adolescents.

\begin{tabular}{lll}
\hline Scale & Delinquency & \\
& $\mathbf{r}$ & $\mathbf{p}$ \\
\hline Father Attachment & $-.230^{* * *}$ & .000 \\
Mother Attachment & $-.220^{* * *}$ & .000 \\
Peer Attachment & $.173^{* * *}$ & .000 \\
\hline
\end{tabular}

Notes: $* * * p<.001$

From the Pearson Product-Moment Correlation analysis, table 1 showed the correlation results between father attachment, mother attachment, peer attachment, and delinquency among adolescents. Father attachment, mother attachment, and peer attachment are significantly correlate with adolescents' delinquency. Based on the results, father attachment $(\mathrm{r}=-.230, \mathrm{p}<.001)$ and mother attachment $(\mathrm{r}=-.220, \mathrm{p}<.001)$ showed negative relationships 
with adolescents' delinquency. Meanwhile, peer attachment $(\mathrm{r}=.173, \mathrm{p}<.001)$ showed a positive relationship with adolescents' delinquency.

Table 2. Mean difference in father attachment, mother attachment, peer attachment, and delinquency between male and female adolescents.

\begin{tabular}{lllll}
\hline Scale & Mean & Standard deviation & $\mathrm{t}$ & $\mathrm{P}$ \\
\hline Delinquency & & & $4.536^{* *}$ & .000 \\
Male & 6.48 & 6.834 & & \\
Female & 3.90 & 5.582 & & \\
\hline
\end{tabular}

Notes: $* * * p<.001$

Table 2 showed the mean difference in delinquency between male and female adolescents where it was tested using the t-test. There was a significant mean difference in adolescents' delinquency between male and female $(\mathrm{t}=4.536, \mathrm{p}<.001)$, where the mean for male and female were 6.48 and 3.90 respectively. The effect size for the differences between gender and delinquency was .041, which is considered small (Cohen, 1988). The small effect size means only $4.1 \%$ of the variance in delinquency is explained by gender.

Table 3. Predictors of delinquency among adolescents

\begin{tabular}{lll}
\hline Variables & $\begin{array}{l}\text { Delinquency } \\
\text { Standardized } \beta\end{array}$ & $\mathrm{p}$ \\
\hline Father attachment & $-.126^{*}$ & .021 \\
Mother attachment & $-.152^{* *}$ & .005 \\
Peer attachment & $.194 * * *$ & .000 \\
Gender & $-.222^{* * *}$ & .000 \\
$\mathrm{R}^{2}$ & .139 & \\
$\mathrm{~F}$ & $17.612 * * *$ & \\
\hline
\end{tabular}

Notes: $* p<.05, * * p<.01, * * * p<.001$

Table 3 showed the multiple regressions between father attachment, mother attachment, peer attachment, gender and delinquency among adolescents. Father attachment $(\beta=-.126, p<.05)$, mother attachment $(\beta=-.152, p<.01)$, peer attachment $(\beta=.194, \mathrm{p}<.001)$, and gender $(\beta=-.222, \mathrm{p}<.001)$ significantly predict the delinquency among adolescents. The $\mathrm{R}^{2}$ was .139 which indicated $13.9 \%$ of the variance in delinquency is explained by the model.

\section{Discussion}

Based on the result from table 1, father and mother attachment have a negative relationship with adolescents' delinquency. This showed that adolescents who are highly attached to their father and mother are less likely to be involved in delinquent behaviors. Parents who are more attached to their children are more aware of their children daily activities and friends that they meet. This reduces the chances of the adolescents to be involved in delinquent behaviors as well as in meeting up delinquent friends. Parents are also able to intervene whenever they suspect their children misbehave or mix up with the wrong group of friends which in turn decreases the delinquency in them (Ingram, Patchin, Huebner, McCluskey \& Bynum, 2007; Warr, 2005).

From table 1, peer attachment is positively related to adolescents' delinquency. This showed that adolescents who are highly attached to their peers are more likely to involve in delinquent behaviors as in previous study (Daigle, Cullen \& Wright, 2007). According to Ingram et al. (2005), peers are strongly related to delinquency where delinquent peers increased the involvement of adolescents in delinquent behaviors. Also, peers are one of the most important social bonds in adolescents' life. Attachment to friends is the important element in social bond where it is related to adolescents' delinquency. Adolescents are more likely to involve in delinquent behaviors when they are strongly attached to their peers especially if their peers involved in delinquency. This is to gain recognition from their friends in order to be in-group (Daigle, Cullen \& Wright, 2007; Ingram et al., 
2007).

The result of the t-test is consistent with past research whereby there was a significant gender difference among males and females adolescents. Males are more likely committing delinquent behaviors compared to females (Daigle, Cullen \& Wright, 2007; Hart \& Mueller, 2013; Hoeve et al., 2012). Males are more likely to involve in delinquency as they are more impulsive and experienced more attention deficit compared to females (Daigle, Cullen \& Wright, 2007). Past research by Higgins and Tewksbury (2006) supported this result where they found out that males have lower self-control, prefer risky behaviors, and have higher opportunity for delinquency which causes them to involve more in delinquent behaviors compared to females. In a local study, it was found that male adolescents are 3 times higher than female adolescents in the involvement of physical fighting and possession of weapons (Lee, Chen, Lee \& Kaur, 2007).

Based on the result in table 3, mother attachment, father attachment, peer attachment, and gender are the predictors of delinquency among adolescents. Gender is the strongest predictor, followed by peer attachment, mother attachment, and lastly father attachment. Gender is the strongest predictor for delinquency where males are more delinquent than females. This showed that gender is more important than attachment in predicting delinquency. Since young, there are gender difference between males and females where males tend to be more aggressive and active. The male hormone, testosterone, increases the dominance and aggressiveness in males (Tieger, 1980). These characteristics have been imprinted in them and are carried throughout their life-span. Also, gender roles contribute to the aggressiveness in the children where boys are stereotyped to be tough and dominant while girls are advised to be polite and nurturing (Wenar \& Kerig, 2006). Consequently, males are more likely to commit delinquent behaviors compared to females.

\section{Conclusion}

This study has investigated the relationships between parental attachment, peer attachment and delinquency among adolescents. One of the limitations of this study is regarding the complexity of the questions on parental attachment, peer attachment, and delinquent behaviors. The result showed that the lower the attachment with father and mother, the higher the delinquent behaviors among adolescents. This means that low parental attachment since childhood causes higher delinquency in adolescents. However, adolescents might get involved in the delinquent behaviors which then reduce their attachment to their parents. Thus, it is the delinquency in the adolescents that causes them to be less attached to their parents. The same also applies in peer attachment and delinquency. Thus, it is suggested that longitudinal research should be conducted in the future to understand the causal of delinquency among adolescents.

The current study is a cross-sectional research where the data was collected in a short period of time during adolescents' stage. The underlining factors that contribute to adolescents' delinquency are unable to be examined. It is also unclear regarding what influence the adolescents' delinquent behavior since childhood. Thus, it is recommended for future study to explore on the adolescents' early life experiences that might influence delinquent behavior.

In conclusion, parental attachment is important since childhood especially to the boys. As the delinquent characteristics have been imprinted in them since they were young, the parents should pay more attention to them in order to prevent delinquent behavior. Moreover, parents should also monitor their children's peers as peer attachment is strongly related to delinquency. Adolescents who are attached to delinquent friends are more likely to involve in delinquent behaviors. Thus, these factors should be considered in implementing intervention to curb delinquency among adolescents in Malaysia.

\section{References}

Adibah, A. S. M. M., Melati, S., \& Zuria, M. (2013). Understanding the experience of female adolescent delinquents: A phenomenological study. IAMURE International Journal of Social Sciences, 5, 1-20. http://dx.doi.org/10.7718/ijss.v5i1.392

Ainsworth, M. D. S. (1969). Object relations, dependency, and attachment: A theoretical review of the infant-mother relationship. Child Development, 40, 969-1025. http://dx.doi.org/10.2307/1127008

Armsden, G., \& Greenberg, M. (1987). The inventory of parent and peer attachment: Individual differences and their relationship to psychological well-being in adolescence. Journal of Youth and Adolescence, 16(5), 427-454. http://dx.doi.org/10.1007/BF02202939

Baker, K. (2006). Understanding violent and antisocial behavior in children and adolescents. Current Paediatrics, 16, 472-477. http://dx.doi.org/10.1016/j.cupe.2006.08.011

Bergin, C., \& Bergin, D. (2009). Attachment in the classroom. Educational Psychological Review, 21, 141-170. http://dx.doi.org/10.1007/s10648-009-9104-0 
Bowlby, J. (Ed.). (1971). Attachment and loss (Vol. 1). Harmondsworth: Penguin.

Cohen, J. (1988). Statistical power analysis for the behavioral sciences (2nd ed.). Hillsdale, NJ: Lawrence Erlbaum Associates.

Daigle, L. E., Cullen, F. T., \& Wright, J. P. (2007). Gender differences in the predictors of juvenile delinquency: Assessing the generality-specificity debate. Youth Violence and Juvenile Justice, 5(3), 254-286. http://dx.doi.org/10.1177/1541204007301289

Department of Social Welfare. (2013). Laporan statistik 2011. Retrieved from http://www.jkm.gov.my/

Drug Report. (2012). National Anti-Drug Agency of Malaysia. Selangor: Putrajaya.

Elgar, F. J., Knight, J., Worrall, G. J., \& Sherman, G. (2003). Attachment characteristics and behavioral problems in rural and urban juvenile delinquents. Child Psychiatry \& Human Development, 34(1), 35-48. http://dx.doi.org/10.1023/A:1025349908855

Gorman-Smith, D. (2008). Urban neighborhoods, families, and juvenile delinquency. Prevention Researcher, 15(1), 17-20.

Hariati, A. (2010, November 7). Troubled and violent teens. TheStar Online. Retrieved from http://thestar.com.my/news/story.asp?file=/2010/11/7/nation/7287853\&sec=nation

Hart, C. O., \& Mueller, C. E. (2013). School delinquency and social bond factors: Exploring gendered differences among a national sample of $10^{\text {th }}$ graders. Psychology in the Schools, 50(2), 116-133.

Higgins, G. E., \& Tewksbury, R. (2006). Sex and self-control theory: The measures and causal model may be different. Youth and Society, 37(4), 479-503. http://dx.doi.org/10.1177/0044118X05283423

Hoeve, M., Stams, G. J. J. M., Put, C. E., Dubas, J. S., Laan, P. H., \& Gerris, J. R. M. (2012). A meta-analysis of attachment to parents and delinquency. Journal of Abnormal Child Psychology, 40, 771-785. http://dx.doi.org/10.1007/s10802-011-9608-1

Houston, J., \& Barton, S. M. (2005). Juvenile justice: theory, systems, and organization. Upper Saddle River, NJ: Prentice Hall.

Immele, A. (2000). The role of adolescents' representations of attachment and peer relationships in the prediction of delinquency. United States: University of Virginia.

Ingram, J. R., Patchin, J. W., Huebner, B. M., McCluskey, J. D., \& Bynum, T. S. (2007). Parents, friends, and serious delinquency: An examination of direct and indirect effects among at-risk early adolescents. Criminal Justice Review, 32(4), 380-400. http://dx.doi.org/10.1177/0734016807311436

Lee, L. K., Chen, P. C. Y., Lee, K. K., \& Kaur, J. (2007). Violence-related behaviors among Malaysian adolescents: A cross sectional survey among secondary school students in Negeri Sembilan. Annals Academy of Medicine, 36(3), 169-174.

Mak, A. (1993). A self-report delinquency scale for Australian adolescents. Australian journal of psychology, 45(2), 75-79. http://dx.doi.org/10.1080/00049539308259122

Maznah, B. (2007). Juvenile delinquency. Malaysia: University Putra Malaysia.

The Commissioner of Law Revision, Malaysia. (2006). Act 505: Administration of Islamic Law (Federal Territories) Act 1993. Kuala Lumpur: Percetakan Nasional Malaysia Berhad.

Tieger, T. (1980). On the biological basis of sex differences in aggression. Child Development, 51(4), 943-963. http://dx.doi.org/10.2307/1129534

Warr, M. (2005). Making delinquent friends: Adult supervision and children's affiliations. Criminology, 43(1), 77-106. http://dx.doi.org/10.1111/j.0011-1348.2005.00003.x

Weerman, F. M., \& Hoeve, M. (2012). Peers and delinquency among girls and boys: Are sex differences in delinquency explained by peer factors? European Journal of Criminology, 9(3), 228-244. http://dx.doi.org/10.1177/1477370811435736

Wenar, C., \& Kerig, P. (2006). Developmental psychopathology: From infancy through adolescence (5th ed.). New York: McGraw-Hill.

\section{Copyrights}

Copyright for this article is retained by the author(s), with first publication rights granted to the journal.

This is an open-access article distributed under the terms and conditions of the Creative Commons Attribution license (http://creativecommons.org/licenses/by/3.0/). 